\title{
Commentary: In vitro analysis of a biological composite valve graft: More evidence in support of the sinuses of Valsalva
}

\author{
Leonard N. Girardi, MD
}

\author{
Department of Cardiothoracic Surgery, Weill Cornell Medical College, New York, NY. \\ Disclosures: Author has nothing to disclose with regard to commercial support. \\ Received for publication Oct 6, 2019; accepted for publication Oct 7, 2019; available ahead of print Oct 24, 2019. \\ Address for reprints: Leonard N. Girardi, MD, Department of Cardiothoracic Surgery, Weill Cornell Medical Col- \\ lege, New York, NY 10065 (E-mail: lngirard@med.cornell.edu). \\ J Thorac Cardiovasc Surg 2021;161:591-2 \\ $0022-5223 / \$ 36.00$ \\ Copyright (c) 2019 by The American Association for Thoracic Surgery \\ https://doi.org/10.1016/j.jtcvs.2019.10.042
}

Since the introduction of a Dacron graft with sinuses of Valsalva (SOV) into the world of aortic root surgery, cardiothoracic surgeons have carried out detailed analyses of the symbiotic biomechanics of the aortic root, aortic valve, and downstream aorta. ${ }^{1}$ Early finite element analysis of the aortic valve leaflets hinted at the potential for less leaflet stress and increased native valve durability when sinuses were recreated during valve-sparing aortic root replacement (VSRR). ${ }^{2}$ However, clinical studies have been unable to discern either short- or long-term benefit to root reconstruction either with or without SOVs. Recent advancements in 4-dimensional (4D) flow magnetic resonance imaging (MRI) have led to illuminating studies (and beautiful pictures) quantifying aortic root hemodynamics, aortic valve leaflet mechanics, downstream aortic stress, and the importance of sinus vorticeal flow in patients who have undergone aortic root replacement both with biological composite valve grafts and VSRR. ${ }^{3,4}$

In this issue of the Journal, Sadri and colleagues ${ }^{5}$ use a validated left heart simulator to perform in vitro analysis of a soon to be commercially available premanufactured aortic valve conduit (AVC). Comparing this new AVC both with $\left(\mathrm{AVC}_{\text {sinus }}\right)$ and without $\mathrm{SOV}\left(\mathrm{AVC}_{\mathrm{no} \mathrm{sinus}}\right)$, the authors calculated aortic valve fluid dynamics as well as aortic valve leaflet kinematics using particle image velocimetry and high-speed imaging. Like all good research, the data they have produced stimulate as many questions as they answer in the quest for the ultimate neo-root that provides optimal aortic root and downstream hemodynamics while creating an environment that promotes lasting native and prosthetic aortic valve durability.

Although it must be noted that this was an industrysponsored study, the authors have done an excellent job of avoiding bias or speculation favoring this new product and, instead, just present us with the facts. When comparing the hemodynamics of the 2 models at 3 different

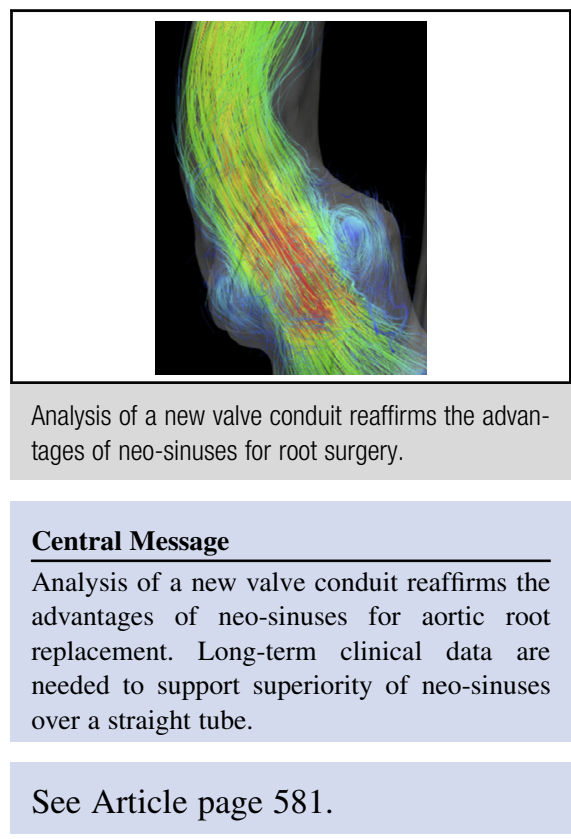

cardiac outputs $(2.5 \mathrm{~L} / \mathrm{min}, 5 \mathrm{~L} / \mathrm{min}$, and $6.5 \mathrm{~L} / \mathrm{min})$, there is significantly lower mean and peak transvalvular pressure gradients and greater prosthetic valve effective orifice area for the $\mathrm{AVC}_{\text {sinus }}$ rather than the $\mathrm{AVC}_{\mathrm{no} \text { sinus. }}$. Although the aortic valve leaflets had similar opening patterns during the early acceleration phase of systole at physiologic cardiac outputs, those in the $\mathrm{AVC}_{\text {sinus }}$ model opened more fully during peak systole, leading to a greater geometric orifice area (GOA).

Particle image velocimetry analysis revealed the vortices in the $\mathrm{AVC}_{\mathrm{no}}$ sinus impinge on the aortic wall during the acceleration phase of systole. This impedes leaflet opening and leads to faster dissipation of energy, a phenomenon previously observed by others. ${ }^{6,7}$ Interestingly, the leaflets in the $\mathrm{AVC}_{\text {sinus }}$ model also closed earlier in the deceleration phase of systole with a corresponding decrease in GOA immediately before valve closure. Although one could speculate that this earlier leaflet closure and reduction in GOA could have detrimental effects on ventricular performance, in vivo $4 \mathrm{D}$ flow MRI analysis has shown that this minor reduction in GOA at the end of systole does not significantly increase the transvalvular pressure gradient. ${ }^{3,8}$ Rather, this reduction in the GOA suggests the SOV maintain the vortices into later 
stages of systole, contributing to their more normal physiologic migration out of the sinuses as they approach the sinotubular junction. The result is smoother leaflet closure with the potential for less shear stress on the aortic valve and, perhaps, enhanced durability.

These findings add more fuel to the fire in the debate between the Valsalva graft and straight graft camps analyzing complex aortic root reconstruction. Although the authors rightly acknowledge that the rigid compliance of their acrylic flow chamber may not replicate the compliance of a Dacron graft in vivo, these findings are quite consistent with those seen with 4D flow MRI analysis of patients after VSRR and CVG replacement. Rather than trying to figure out whether the next iteration of an operation is better after we've already taken it to the operating room, the development of more physiologic in vitro models may allow us to preemptively examine the impact (some potentially negative) that prophylactic proximal aortic operations have on downstream hemodynamics.

\section{References}

1. De Paulis R, De Matteis GM, Nardi P, Scaffa R, Colella DF, Chiarello L. A new aortic Dacron conduit for surgical treatment of aortic root pathology. Ital Hear J. 2000;1:457-63.

2. Grande-Allen KJJ, Cochran RP, Reinhall PG, Kunzelman KS. Re-creation of sinuses is important for sparing the aortic valve: a finite element study. $J$ Thorac Cardiovasc Surg. 2000;119:753-63.

3. Oechtering TH, Hons CF, Sieren M, Hunold P, Hennemuth A, Huellebrand M, et al. Time-resolved 3-dimensional magnetic resonance phase contrast imaging (4D Flow MRI) analysis of hemodynamics in valve-sparing aortic root repair with an anatomically shaped sinus prosthesis. J Thorac Cardiovasc Surg. 2016; 152:418-27.

4. Gaudino M, Piatti F, Lau C, Sturla F, Weinsaft JW, Weltert L, et al. Aortic flow after valve sparing root replacement with or without neosinuses reconstruction. J Thorac Cardiovasc Surg. 2019;157:455-65.

5. Sadri V, Madukauwa-David ID, Yoganathan AP. In vitro evaluation of a new aortic valved conduit. J Thorac Cardiovasc Surg. 2021;161:581-90.e6.

6. Pisani G, Scaffa R, Ieropoli O, Dell'Amico EM, Maselli D, Morbiducci U, et al. Role of the sinuses of Valsalva on the opening of the aortic valve. J Thorac Cardiovasc Surg. 2013;145:999-1003.

7. Markl M, Draney MT, Miller DC, Levin JM, Williamson EE, Pelc NJ, et al. Velocity mapping of aortic flow in healthy volunteers and patients after valve-sparing aortic root replacement. Technology. 2005;130:456-63.

8. Galea N, Piatti F, Lau C, Sturla F, Weltert L, Carbone I, et al. 4D flow characteristics of aortic blood flow after valve sparing root reimplantation procedure. $J$ Vis Surg. 2018;4:95-9. 